\title{
The prevalence and characteristics of Helicobacter pylori-associated gastritis in dyspeptic patients in Eastern Croatia, determined by immunohistochemistry
}

\author{
NIKOLINA BRKIĆa,b,* \\ VELIMIR TERZIĆc,d \\ MARIJA ŠVAGELJe \\ MIRTA CVRKOVIĆ $f$ \\ HRVOJE BRKIĆg \\ DRAŽEN ŠVAGELJf,h \\ ${ }^{a}$ General Hospital Vinkovci, Vinkovci

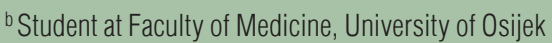 \\ Croatia \\ 'Department of Urology, General Hospital Vinkovci \\ Vinkovci, Croatia \\ dPhD candidate at Faculty of Medicine \\ University of Osijek, Croatia \\ ${ }^{e}$ Department of General Surgery with Traumatology \\ General Hospital Vinkovci, Vinkovci, Croatia \\ 'Department of Pathology and Cytology \\ General Hospital Vinkovci, Vinkovci, Croatia \\ ${ }^{g}$ Faculty of Medicine, University of Osijek, Department \\ of biophysics and radiology, Osijek, Croatia \\ hFaculty of Medicine, University of Osijek, Department \\ of Pathology and Forensic Medicine, Osijek, Croatia \\ Correspondence: \\ Nikolina Brkić \\ E-mail: nikolinatarbuk@gmail.com \\ Key words: Helicobacter pylori, prevalence, Croatia, \\ chronic active gastritis, immunohistochemistry
}

Nikolina Brkić and Velimir Terzić has equally contributed to this paper

Received May 15, 2016.

Revised December 19, 2016

Accepted January 10, 2017.

\section{Abstract}

Background and purpose: Helicobacter pylori $(H p)$, which is associated with many upper gastrointestinal diseases, is found in about half of world's population. Aim od this study is to reveal the prevalence and characteristics of Hp-associated gastritis in dyspeptic patients in the population of Croatia.

Materials and methods: Retrospective analysis the data and materials of 871 dyspeptic patients undergoing routine endoscopy. The gastric biopsy specimens were stained by Hp-specific immmunohistocemical stain. Endoscopic and pathology findings were recorded for $\mathrm{Hp}$ infection and the presence of active gastritis. Nominal variables in the case of a large number of samples were compared using Pearson $\chi^{2}$ test, while in the case of a small number of samples was used Fisher's Exact test.

Results: In the present study determined prevalence of Hp-associated gastritis in the population of Croatia is $41 \%$. Chronic active gastritis was found in 94\% of patients with Hp infection and 5\% of patients with gastritis of some other etiology. Gastric mucosal atrophy was observed in 5\% of patients older than 40 years. Intestinal metaplasia was detected in $26 \%$ of patients. Severe intestinal metaplasia occurs in the age group older than 60 years.

Conclusion: This study is the first large study of Hp prevalence by histological and immunohistochemical methods in Croatia, so the results of this study contribute to the understanding of how big a public health problem is Hp infection in a population of Croatia.

\section{INTRODUCTION}

Gelicobacter pylori $(\mathrm{Hp})$ is a spiral, Gram-negative bacterium which 1 was discovered in 1982 by Marshall and Warren (1). Hp chronically colonizes the human stomach and is currently recognized to play a causative role in the pathogenesis of various gastroduodenal diseases, including gastritis, peptic ulcers, gastric cancer and mucosa-associated lymphoid tissue lymphoma (2-4).

$\mathrm{Hp}$ is a highly heterogeneous bacterium and its virulence varies geographically. The explanation for geographic differences in the incidence of gastric cancer and the role of $\mathrm{Hp}$ infection in gastric cancer and duodenal, could be the presence of different types of $\mathrm{Hp}$ virulence factor, especially CagA (cytotoxin-associated gene A), VacA (vacuolating cytotoxin), OipA (outer inflammatory protein) and DupA (outer inflamma- 
tory protein). Some studies have been reported that individuals infected with $\mathrm{CagA}$ - positive strains of $\mathrm{Hp}$ are at a higher risk of peptic ulcer or gastric cancer than those infected with CagA-negative strains. In some researches DupA is confirmed as a risk factor for duodenal ulcer. (5)

Hp shows a remarkable allelic diversity and a large genetic variability, resulting that every individual is infected with Hp's unique strain, but differences between relatives are minimal. Rapid development of high-level resistance to commonly used antibiotics could be explained by a significantly higher mutation rate than found in many other bacteria. (6)

Several diagnostic tests are available for the detection of $\mathrm{Hp}$ and they could be divided in group of invasive and non-invasive tests. Each of these tests has its usefulness and limitations in different clinical situations. Invasive tests include histology, culture, rapid urease test and molecular methods, and they are performed through endoscopic biopsy specimens. The most widely used non-invasive tests are urea breathing test and stool antigen. In the epidemiological studies the most used non-invasive test is serology. (7)

Histological method of detection Hp infecton has been considered to be the gold standard. It is widely available and capable of achieving sensitivity and specificity of more than $95 \%$, also has the ability to evaluate for pathologic changes associated with $\mathrm{Hp}$ infection such as inflammation, atrophy, intestinal metaplasia and malignancy. (7)

Besides heamtoxylin and eosin (H\&E) staining of histological preparations, there are several histochemical staining methods that can improve visualization of microorganisms including Warthin-Starry, Modified Giemsa, Modified Genta, and Hp silver stain. Sensitivity of $\mathrm{H} \& \mathrm{E}$ is comparable to that of Giemsa and Genta, but the specificity is decreasing in low Hp density (90\%). Warthin-Starry silver staining allows an excellent visualization, but it is expensive, time consuming and the results are not always reliable. Some researchers showed that immunohistochemical staining (IHC) with specific Hp antibodies has the highest sensitivity and specificity. A significant advantage of IHC is assessing the presence of $\mathrm{Hp}$ even if in biopsy specimen are coccoid forms of $\mathrm{Hp}$. (7)

According to the Croatian national guidelines 2014, for the diagnosis of $\mathrm{Hp}$ infection should be applied a different diagnostic approach in patients according to age. In the group of patients younger than 45 years, without alarming symptoms (weight loss, dysphagia, signs of gastrointestinal bleeding, palpable resistance in the stomach, iron deficiency anemia) diagnostic procedure can be performed through the non-invasive diagnostic methods. After treatment they also should be tested noninvansively to evaluate succes of therapy. For group of patients older than 45 years, and all those present with alarm symptoms, regardless of age, it is recommended to be tested with endoscopy and invasive methods. (8)
Guidelines from the last Consensus Conference (Maastricht V) did not change significantly for all populations with a prevalence of $\mathrm{Hp}$ infection over $20 \%$ (this is the case in Croatia). It was suggested that the age limit between non-invasive and invasive diagnostic methods of $\mathrm{Hp}$ infection should be determined by the prevalence of gastric cancer in a given population. (9)

\section{METHODS}

\section{Population study}

This study was conducted at Department of Pathology and Cytology of General Hospital Vinkovci and was approved by Ethics Committee of the General Hospital Vinkovci. The data and biopsy materials of dyspeptic patients undergoing routine endoscopy from two-year period $(2011-2012)$ are analyzed. Patients who were in the control gastroscopy after Hp eradication therapy and patients whose findings were insufficient samples were not taken into account.

\section{Endoscopy and biopsy sample}

Samples of gastric biopsies were taken during endoscopy, four gastric biopsy were obtained (two from the antrum and two from the corpus). Two pathologists analyzed samples at the Department of Pathology and Cytology of General Hospital Vinkovci.

\section{Histochemistry and immunohistochemistry}

Histological features such as gastric mucosal changes for any evidence of gastritis were studied on $\mathrm{H} \& \mathrm{E}$-stained sections and was evaluated according to the updated Sydney system (10). The degree of bacterial load was classified into four grades: 0 „normal“, 1 „mild“, 2 „moderate“, 3 „marked“.

Immunohistochemical staining, also used by Tajalli et al. (11), was performed with the concentrated primary antibody, anti-Hp polyclonal rabbit (DakoCytomation), at a dilution 1:150 with Envision Flex antibody diluent, using the device for automated immunohistochemical staining AUTOSTAINER Link (Dako). Antigen cells in deparaffinized sections were unmasked by treatment with the PT-Link (109 Dako PT) in Target Retrieval Solution, High $\mathrm{pH}$ 9. The secondary antibody (streptavidin peroxidase) is used from the set LSAB + System, HRP (Dako). Preparations are contrasted with hematoxylin 2 minutes.

\section{Statistical analysis}

Nominal variables in the case of a large number of samples were compared using Pearson $\chi^{2}$ test, while in the case of a small number of samples was used Fisher's Exact test. In numerical comparisons with nominal variables, with a normal distribution of numerical variables was used parametric Student's t-test. The level of significance was $\mathrm{p}<0.05$. 
Table 1. The prevalence of Hp infection by age groups

\begin{tabular}{|lcccc|}
\hline & $\mathrm{Hp}+(\mathrm{n})$ & $\mathrm{Hp}-(\mathrm{n})$ & $\mathrm{Hp}+(\%)$ & $\mathrm{Hp}-(\%)$ \\
\hline$\leq 20$ & 3 & 14 & 18 & 82 \\
$21-30$ & 14 & 34 & 29 & 71 \\
$31-40$ & 41 & 55 & 43 & 57 \\
$41-50$ & 71 & 75 & 48 & 52 \\
$51-60$ & 98 & 137 & 42 & 58 \\
$>60$ & 133 & 196 & 40 & 60 \\
\hline
\end{tabular}

Hp: Helicobacter pylori

\section{RESULTS}

In this study, 410 male and 461 female patients were included. Patients were divided into six groups: younger than 20 years $(n=17), 21-30$ years $(n=48), 31-40$ years $(\mathrm{n}=96), 41-50$ years $(\mathrm{n}=146), 51-60$ years $(\mathrm{n}=235)$, older than 60 years $(n=329)$.

Of the total number of patients, in $41 \%$ is determined presence of $\mathrm{Hp}$. There is no statistically remarkable difference between the sexes $(\mathrm{p}=0.531)$. The prevalence of $\mathrm{Hp}$ infection by age groups is shown in Table 1 .

In the age group 41-50 years occurs the plateau of $\mathrm{Hp}$ infection (48\%), followed by decreasing to $40 \%$ in the age group older than 60 .

Hp was found in the antrum and corpus of $77 \%$ of patients, in $19 \%$ only in the corpus and in $4 \%$ only in the antrum. The intensity of the $\mathrm{Hp}$ according to localization is shown in Table 2.

Chronic active gastritis was found in 94\% patients in $\mathrm{Hp}$ positive group and in 5\% patients in $\mathrm{Hp}$ negative group. Pangastritis prevalents in both sexes (men 68\% and women $62 \%$ ). After pangastritis in men is more common antral gastritis (20\%), while in women corpus gastritis $(24 \%) \cdot \chi^{2}$ test showed a statistically remarkable difference in the occurrence of chronic active gastritis in relation to the region of the stomach between the sexes $(\mathrm{p}$ $=0.005$ ).

Analysis of the components of inflammation in the mucosa of the stomach has shown that in the antrum and corpus predominates moderate acute component of inflammation (2+) and marked chronic inflammation (3+).

Table 2. The intensity of the Hp according to localization

\begin{tabular}{|lcccccc|}
\hline & & Hp (n) & \multicolumn{3}{c|}{ Hp (\%) } \\
\hline & + & ++ & ++ & + & ++ & +++ \\
\hline Antrum & 77 & 107 & 106 & 26 & 37 & 37 \\
Corpus & 75 & 163 & 107 & 22 & 47 & 31 \\
\hline
\end{tabular}

Hp: Helicobacter pylori
Remarkable correlation between the Hp and acute inflammatory components was found in the antrum of both sexes, while in the corpus is confirmed only in men (with correlation coefficient $r$ ranging from \pm 0.40 to \pm 0.70 ). In the antrum in both sexes and in the corpus in men exists mild correlation between the $\mathrm{Hp}$ and chronic inflammation ( $\mathrm{r} \pm 0.20$ to \pm 0.40$)$.

Atrophy of the gastric mucosa is found in 5\% patients in $\mathrm{Hp}$ positive group, and in $3.5 \%$ patients $\mathrm{Hp}$ negative group. In $\mathrm{Hp}$ positive group the antrum is atrophic changed in $72 \%$ patients, the corpus in $22 \%$, and in $6 \%$ of patients atrophy affects antrum and corpus. Severe atrophy occurs in patients older than 60 years.

Intestinal metaplasia of gastric mucosa was found in $26 \%$ patients in the Hp positive group and in $25 \%$ patients in the Hp negative group. In $88 \%$ patients intestinal metaplasia was found in the antrum, in $8 \%$ engages the antrum and corpus, and in $4 \%$ patients was found only in the corpus. The most of the patients had mild metaplasia, while severe metaplasia occurs only in the group of patients older than 60 years.

In Table 3 are comparatively shown the most remarkable changes ( $\mathrm{Hp}$, intestinal metaplasia, atrophy) in relation to the localization.

Table 3. Comparison of the most remarkable changes in relation to a localization

\begin{tabular}{|lccc|}
\hline & $\begin{array}{c}\text { Hp presence } \\
(\%)\end{array}$ & $\begin{array}{c}\text { Atrophy } \\
(\%)\end{array}$ & $\begin{array}{c}\text { Intestinal } \\
\text { metaplasia (\%) }\end{array}$ \\
\hline Antrum & 4 & 72 & 88 \\
Corpus & 19 & 22 & 4 \\
Antrum & 77 & 6 & 8 \\
and corpus & & & \\
\hline
\end{tabular}

Hp: Helicobacter pylori

\section{DISSCUSIONS}

It is assumed that about $50 \%$ of the world's population is infected with Hp. Seroprevalence of Hp infection in the population differs in developing and developed countries. Serologic indicators of $\mathrm{Hp}$ infection in developed countries are rarely positive in children younger than 10 years and prevalence grow to $10 \%$ in age group $18-30$ years, whereas the maximum $(50 \%)$ of the infection is reached only after the age of 60 (12). Developing countries are characterized by the majority of children infected before the age of 10 , with a plateau of the infection (over $80 \%$ ) before the age of $50(13,14)$

Epidemiological studies frequently are using serological tests for $\mathrm{Hp}$ infection detection, because of their inexpensiveness, rapidity and acceptability to patients. Serological tests are useful for evaluation of $\mathrm{Hp}$ infection in children. The other advantage of serological test is that 
the accuracy of serological tests is not affected by ulcer bleeding, gastric atrophy as well as the use of PPI or antibiotics, which cause false negative results in other invasive or noninvasive tests. Because the serological tests detect antibodies that can persist in the blood for long periods after infection is cured, they do not distinguish between active infection and past exposure and are not suitable for evaluation in the eradication therapy. (15)

Croatia is located at the crossroads of Mediterranean, Central and Southeast Europe. In Europe, the prevalence of Hp seems to be lower in Northern countries (the Netherlands 32\%) than in Southern (Portugal 84\%) and Eastern countries (Turkey 83\%) (16). Review article, which covers 22 of the 35 European countries, based on 44 studies, cites prevalence which ranges from $17 \%$ in Denmark to $88 \%$ in Russia (17). In Croatian population in 1997 seroprevalence of $\mathrm{Hp}$ infection was between $60 \%$ and 68\% (18). The latest epidemiological study in Croatia, conducted ELISA, showed seroprevalence of $\mathrm{Hp}$ infection $92 \%$ in dyspeptic patients and $64 \%$ in the control group of voluntary blood donors (19).

This study is the first large study of $\mathrm{Hp}$ prevalence by histological and immunohistochemical methods in Croatia, so the results of this study contribute to the understanding of how big a public health problem is $\mathrm{Hp}$ infection in a population of Croatia.

The prevalence of $\mathrm{Hp}$ infection in this study is determined to be $41 \%$ putting Croatia between developed and developing countries, which can be compared with the results of histological studies: $71 \%$ in Turkey (20), 69\% in Morocco (21), 66\% in Vietnam (22), 62\% in Bhutan (23), $50 \%$ in India (24), 54\% of Albanians and 34\% of the Greeks (25), $42 \%$ in Hungary (17), 38\% in Canada (16), $4 \%$ to $29 \%$ in large sample of patients $(78,985)$ from 35 U.S. states (26), Puerto Rico and Colombia, 15\% in Belgium (17), 7\% in 251 patients in USA (27).

The plateau of $\mathrm{Hp}$ infection occurs in the age group 41-50 years (48\%), which coincides with the research Joutei et al. in Morocco (21), while Sonnenberg et al. (27) states plateau at the age group 30-39 years.

Vilaichone et al. (23) reported decreasing of the prevalence of $\mathrm{Hp}$ infection in the population older than 60 (43\%) which correlates with our results, in contrast to Nguyen et al. (22) which quotes the increase in prevalence $(75 \%)$ in the same age group.

Chronic active gastritis was present in $94 \%$ patients in $\mathrm{Hp}$ positive group, while in the Hp negative group is present in only $5 \%$ patients. Nguyen et al. (22) cites $83 \%$ of chronic active gastritis in the $\mathrm{Hp}$ positive group, which correlates with our research. In other studies whose results were compared, the percentage of patients with chronic active gastritis is less than $40 \%(24,27,28)$.

Remarkable correlation is reported between the severity of gastritis and grade of $\mathrm{Hp}$ infection which is in accordance with several other authors (29-31).
Gastric mucosal atrophy was observed in 5\% of patients which can be compared with study in India (24) and was lower than in other studies: in Vietnam 85\% (22), in Sweden 55\% (28), in Italy 24\% (32), in Iran 45\% (33).

Our results show intestinal metaplasia of gastric mucosa in 26\% patients in the Hp positive group and in $25 \%$ patients in the Hp negative group. Other researches show a lower percentage of patients with intestinal metaplasia of the stomach mucose: in Turkey $18 \%$ (20), in Vietnam $15 \%$ (22), in USA $2 \%$ to $17 \%$ (27), in India $2 \%$ (24).

The recommended primary therapy for $\mathrm{Hp}$ infection includes: a proton pump inhibitor (PPI) and antibiotic (clarithromycin, and amoxicillin or metronidazole). Recent studies have shown a significant decline in the effectiveness of conventional therapy, caused by an increase in primary resistance of $\mathrm{Hp}$ to clarithromycin. Although the primary resistance to metronidazole in many European countries is relatively high, this problem can be overcome by increasing the dose and longer treatment or the addition of bismuth preparations.

In addition to conventional therapy, there is sequential therapy based on the hypothesis that during the first stage treatment amoxicillin reduces the number of mutants resistant to clarithromycin, so that in the second stage of the therapy application of clarithromycin is more efficiently. Sequential therapy is conducted such that the first five days administered amoksiclin + PIP, then the next five days clarithromycin + metronidazole + PPI

After the failure of PPI-triple therapy (PPI-metronidazole-amoxicillin) for 10-14 days or sequential therapy for a period of 10 days, in the guidelines recommended therapy is quad therapy with bismuth - 10 days or PPI triple therapy which contains levofloxacin -10 days. (8)

\section{CONCLUSIONS}

The prevalence of $\mathrm{Hp}$ infection in this study is determined to be $41 \%$ putting Croatia between developed and developing countries.

Chronic active gastritis was present in $94 \%$ patients in Hp positive group. Pangastritis prevalents in both sexes (men 68\% and women 62\%). After pangastritis in men is more common antral gastritis $(20 \%)$, while in women corpus gastritis (24\%).

Atrophy of the mucosa of the stomach was found in $5 \%$ of patients, and severe atrophy occurs in age group older than 60 years.

Complete (intestinal) metaplasia was found in 26\% and incomplete metaplasia in $1 \%$ of patients. In all age groups most of the patients had mild intestinal metaplasia.

Acknowledgments and disclosures: The authors declare no conflict of interest. 


\section{REFERENCES}

1. MARSHALL B, WARREN JR. Unidentified curved bacilli in the stomach of patients with gastritis and peptic ulceration. The Lancet. 1984;323(8390):1311-5.

https://doi.org/10.1016/S0140-6736(84)91816-6

2. WOTHERSPOON A, ORTIZ-HIDALGO C, FALZON M, ISAACSON P. Helicobacter pylori-associated gastritis and primary B-cell gastric lymphoma. The Lancet. 1991;338(8776):11756. https://doi.org/10.1016/0140-6736(91)92035-Z

3. PEEK RM, BLASER MJ. Helicobacter pylori and gastrointestinal tract adenocarcinomas. Nature Reviews Cancer. 2002;2(1):28-37. https://doi.org/10.1038/nrc703

4. FRANCO AT, JOHNSTON E, KRISHNA U, YAMAOKA Y, ISRAEL DA, NAGY TA, et al. Regulation of gastric carcinogenesis by Helicobacter pylori virulence factors. Cancer research. 2008;68(2):379-87. https://doi.org/10.1158/0008-5472.CAN-07-0824

5. YAMAOKA Y. Mechanisms of disease: Helicobacter pylori virulence factors. Nature Reviews Gastroenterology and Hepatology. 2010;7(11):629-41. https://doi.org/10.1038/nrgastro.2010.154

6. BAUER B, MEYER TF. The human gastric pathogen Helicobacter pylori and its association with gastric cancer and ulcer disease. Ulcers. 2011;2011.

7. CHEY W, WONG B. Practice Parameters Committee of the American College of Gastroenterology American College of Gastroenterology guideline on the management of Helicobacter pylori infection. Am J Gastroenterol. 2007;102(8):1808-25. https://doi.org/10.1111/j.1572-0241.2007.01393.x

8. KATICIĆ M, DUVNJAK M, KANIZAJ T, KRZNARIĆ Z, MARUSIĆ M, MIHALJEVIĆ S, et al. [Croatian guidelines for diagnostics and treatments of Helicobacter pylori infection]. Lijecnicki vjesnik. 2013;136(1-2):1-17.

9. MALFERTHEINER P, MEGRAUD F, O'MORAIN C, GISBERT J, KUIPERS E, AXON A, et al. Management of Helicobacter pylori infection-the Maastricht V/Florence Consensus Report. Gut. 2016:gutjnl-2016-312288.

10. DIXON MF, GENTA RM, YARDLEY JH, CORREA P. Classification and grading of gastritis: the updated Sydney system. The American journal of surgical pathology. 1996;20(10):1161-81. https://doi.org/10.1097/00000478-199610000-00001

11. TAJALLI R, NOBAKHT M, MOHAMMADI-BARZELIGHI H, AGAH S, RASTEGAR-LARI A, SADEGHIPOUR A. The immunohistochemistry and toluidine blue roles for Helicobacter pylori detection in patients with gastritis. Iran Biomed J. 2013; 17(1):36-41

12. GOH KL, CHAN WK, SHIOTA S, YAMAOKA Y. Epidemiology of Helicobacter pylori infection and public health implications. Helicobacter. 2011;16(s1):1-9.

https://doi.org/10.1111/j.1523-5378.2011.00874.x

13. HUNT R, XIAO S, MEGRAUD F, LEON-BARUA R, BAZZOLI F, VAN DER MERWE S, et al. Helicobacter pylori in developing countries. World Gastroenterology Organisation Global Guideline. J Gastrointestin Liver Dis. 2011;20(3):299-304.

14. FRENCK JR RW, CLEMENS J. Helicobacter in the developing world. Microbes and infection. 2003;5(8):705-13. https://doi.org/10.1016/S1286-4579(03)00112-6

15. WANG Y-K, KUO F-C, LIU C-J, WU M-C, SHIH H-Y, WANG SS, et al. Diagnosis of Helicobacter pylori infection: Current options and developments. World Journal of Gastroenterology: WJG. 2015;21(40):11221. https://doi.org/10.3748/wjg.v21.i40.11221

16. EUSEBI LH, ZAGARI RM, BAZZOLI F. Epidemiology of Helicobacter pylori infection. Helicobacter. 2014;19(s1):1-5. https://doi.org/10.1111/hel.12165

17. ROBERTS S, MORRISON-REES S, SAMUEL D, THORNE K, AKBARI A, WILLIAMS J. Review article: the prevalence of Helicobacter pylori and the incidence of gastric cancer across Eu- rope. Alimentary pharmacology \& therapeutics. 2016;43(3):33445. https://doi.org/10.1111/apt.13474

18. BABUŠ V, PRESEČKI V, KATIČIĆ M, BALIJA M, ZORIĆ I, KRONJA L, et al. Rasprostranjenost infekcije s Helicobacter pylori u odrasloj populaciji Hrvatske. Liječnički vjesnik. 1997;119(56):139-42.

19. MARUŠIĆ M, PRESEČKIV, KATIČIĆ M, BILIĆ A, JURČIĆ D, SCHWARZ D. Seroprevalence of Helicobacter pylori infection in dyspeptic patients. Collegium antropologicum. 2008;32(4):1149-53.

20. OZDIL K, SAHIN A, KAHRAMAN R, YUZBASIOGLU B, DEMIRDAG H, CALHAN T, et al. Current prevalence of intestinal metaplasia and Helicobacter pylori infection in dyspeptic adult patients from Turkey. Hepato-gastroenterology. 2009;57(104):1563-6.

21. JOUTEI H, HILALI A, FECHTALI T, RHALLABI N, BENOMAR H. [Helicobacter pylori infection in 755 patients with digestive complaints: Pasteur Institute, Morocco, 1998-2007]. Eastern Mediterranean health journal= La revue de sante de la Mediterranee orientale $=$ al-Majallah al-sihhiyah li-sharq al-mutawassit. 2010;16(7):778-82.

22. NGUYEN TL, UCHIDA T, TSUKAMOTO Y, TRINH DT, TA L, MAI BH, et al. Helicobacter pylori infection and gastroduodenal diseases in Vietnam: a cross-sectional, hospital-based study. BMC gastroenterology. 2010;10(1):114. https://doi.org/10.1186/1471-230X-10-114

23. VILAICHONE RK, MAHACHAI V, SHIOTA S, UCHIDA T, RATANACHU-EK T, TSHERING L, et al. Extremely high prevalence of Helicobacter pylori infection in Bhutan. World journal of gastroenterology : WJG. 2013 May 14;19(18):2806-10. https://doi.org/10.3748/wjg.v19.i18.2806

24. SHUKLA S, PUJANI M, AGARWALA, PUJANI M, ROHTAGI A. Correlation of serology with morphological changes in gastric biopsy in Helicobacter pylori infection and evaluation of immunohistochemistry for $H$. pylori identification. Saudi journal of gastroenterology: official journal of the Saudi Gastroenterology Association. 2012;18(6):369.

25. KATSANOS KH, TATSIONI A, TSAKIRIS V, CHRISTODOULOU D, TSIANOS EV. Helicobacter pylori is a major public health priority in western Balkans: An endoscopy referral center experience. European journal of internal medicine. 2010;21(4):3069. https://doi.org/10.1016/j.ejim.2010.04.004

26. MCJUNKIN B, SISSOKO M, LEVIEN J, UPCHURCH J, AHMED A. Dramatic Decline in Prevalence of Helicobacter pylori and Peptic Ulcer Disease in an Endoscopy-referral Population. The American journal of medicine. 2011;124(3):260-4. https://doi.org/10.1016/j.amjmed.2010.11.013

27. SONNENBERG A, LASH RH, GENTA RM. A National Study of Helicobactor pylori Infection in Gastric Biopsy Specimens. Gastroenterology. 2010;139(6):1894-901. e2.

28. PETERSSON F. Chronic gastritis in a sample of the general population: Helicobacter pylori infection, metaplastic transformation, epithelial proliferation, $\mathrm{p} 53$-and $\mathrm{p} 21$ expression and antral mucosal gastrin content with reference to gastric carcinoma development. 2004.

29. TOKUNAGA Y, SHIRAHASE H, YAMAMOTO E, INAO R, HAMAGUCHI S, KANAJI K, et al. Modified rapid urease test for Helicobacter pylori detection in relation to an immunohistochemical stain. Journal of gastroenterology and hepatology. 2000;15(6):617-21. https://doi.org/10.1046/j.1440-1746.2000.02213.x

30. PEREZ-PEREZ G, BROWN W, COVER T, DUNN B, CAO P, BLASER M. Correlation between serological and mucosal inflammatory responses to Helicobacter pylori. Clinical and diagnostic laboratory immunology. 1994;1(3):325-9.

31. TOKUNAGA Y, SHIRAHASE H, YAMAMOTO E, GOUDA Y, KANAJI K, OHSUMI K. Semiquantitative evaluation for diagnosis of Helicobacter pylori infection in relation to histological 
changes. The American journal of gastroenterology. 1998;93(1):269. https://doi.org/10.1111/j.1572-0241.1998.026_c.x

32. NARDONE G, ROCCO A, STAIBANO S, MEZZA E, AUTIERO G, COMPARE D, et al. Diagnostic accuracy of the serum profile of gastric mucosa in relation to histological and morphometric diagnosis of atrophy. Alimentary pharmacology \& thera- peutics. 2005;22(11-12):1139-46.

https://doi.org/10.1111/j.1365-2036.2005.02734.x

33. HASHEMI MR, RAHNAVARDI M, BIKDELI B, DEHGHANI

ZAHEDANI M. H pylori infection among 1000 southern Iranian dyspeptic patients. World Journal of Gastroenterology. 2006;12(34):5479. https://doi.org/10.3748/wjg.v12.i34.5479 